\title{
A Literature Review of Emotional Labor and Emotional Labor Strategies
}

\author{
Yeong-Gyeong Choi ${ }^{*}$, Kyoung-Seok Kim \\ Business Administration/Kyungpook, Naional University, South Korea
}

Copyright (C) 2015 by authors, all rights reserved. Authors agree that this article remains permanently open access under the terms of the Creative Commons Attribution License 4.0 International License

\begin{abstract}
This study, literature review research, intends to deal with the problem of conceptual ambiguity among research on emotional labor, and to look into the evolutionary trends and changing aspects of defining the concept of emotional labor. For this, it gropes for methods for reducing conceptual ambiguity. Further, it arranges the concept of emotional labor; and examines and reviews comparatively the currents of the existing studies and looks for the characteristics and correlations of their classification criteria. That is, this study intends to arrange systematically and examine theories on emotional labor suggested hitherto, and suggest a future direction of research on emotional labor on the basis thereof. In addition, it attempts to look for positive aspects of the results of emotional labor.
\end{abstract}

Keywords Emotion Labor, Dimensions of Emotional Labor, Surface Acting, Deep Acting

\section{Introduction}

A framework for research on emotion in organizations has been created since emotion was recognized as one element of labor from the 1970s. As the service industry has developed, emotional laborers, who are asked by organizations to hide their emotions and display emotions customers want, have increased rapidly. According as it has been found that emotional labor has negative effects on emotional laborers' attitudes towards jobs and organizations and on their job performance as well as on their psychological and physical health, a lot of studies on emotional laborers have been under way. Many of the studies emphasized negative aspects of the results of emotional labor.

While active research has been carried out by researchers, mixed findings and many problems have been suggested. This is because the existing studies failed to clarify the concept and dimensions of emotional labor. Most research on emotional labor used Hochschild, Morris \& Feldman's concept, and had no clear definition of emotional labor. In addition, different researchers used the different numbers and names of the dimensions of emotional labor.

Hence, this study, literature review research, intends to deal with the problem of conceptual ambiguity among research on emotional labor, and to look into the evolutionary trends and changing aspects of defining the concept of emotional labor. For this, it gropes for methods for reducing conceptual ambiguity. Further, it arranges the concept of emotional labor; and examines and reviews comparatively the currents of the existing studies and looks for the characteristics and correlations of their classification criteria.

That is, this study intends to arrange systematically and examine theories on emotional labor suggested hitherto, and suggest a future direction of research on emotional labor on the basis thereof. In addition, it attempts to look for positive aspects of the results of emotional labor.

\section{Literature Review}

\subsection{Importance of Emotion}

Emotion of individuals, as members of organizations, has long been the topic of research in business administration. The important thing is that the concept of emotional labor in the past was studied in terms of sales and profit increase based on organizational effectiveness, not in terms of the value of individuals.

Although an organization also needs to be treated as an organism, it is clear that the presence of individuals in the framework of performance-based thinking of the organization has been less emphasized.

In general, it is obvious that the concept of emotion is an essential factor for individuals to maintain their own selves and smoothly interact with others (Goffman, 1969). As mentioned earlier, however, emotion in terms of business administration to date has been treated as a factor that interrupts work efficiency in the field (Ashforth and Humphrey, 1993).

In other words, emotion has not been a considering factor 
to increase organizational effectiveness. Since scientific management (Taylor, 1913), a number of studies on business administration have also developed the theories under the premise that emotion is reasonable and rational. Recently, however, as the effect of emotion of organizational members on the entire organization has started to increase, it is now a common norm that emotion needs to be managed at the organizational level (Ashforth and Humphrey, 1993). Furthermore, Cooper and Sawaf (1998) suggested that it is important to strike a balance between intelligence ability and emotional ability of the members.

The Affective Events Theory (AET) of Weiss and Cropanzano (1996) that strongly emphasizes the importance of emotion shows how important the emotion of the members is in organizational management.

The theory suggests that the working conditions in an organization not only directly affect job attitude and behavior of the members, but affect their emotion, such as psychological frustration, as well. It also states that the positive or negative effects are moderated by individual characteristics of the members. Eventually, the AET model was the starting point for the studies on the effect of emotional factors of the members of an organization on the entire performance of the organization. The model suggested that the performance of an organization, which is organizational effectiveness, needs to also include the emotional response of the members, in addition to the official profits.

\subsection{Antecedents of Emotional Labor}

\subsubsection{Individual characteristics}

Of the antecedents that affect emotional labor, the variables related to individual characteristics are emotional contagion, empathic concern and job emotion.

Emotional contagion refers to a congenital sensitivity of a natural assimilation with the emotion expressed by others, where a process of cognitive interpretation is not involved in sharing the emotion with others. People with emotional contagion easily empathize with others emotionally because they express their emotion easily, but feel stressed quickly when they suppress their emotion. Thus, emotional contagion can positively affect emotional labor (Kruml\& Geddes, 2003). Chu (2002) found that emotional contagion has a significant effect on the deep acting of employees. In contrast, Choi et al. (2006) revealed that emotional contagion affects surface acting. It is inferred that the difference in the results is attributable to the difference in samples.

One of the individual characteristics that affect emotional labor is empathic concern. Unlike emotional contagion, in which individuals take other's emotion as their own, empathic concern refers to individuals' self-centered acceptance of and response to other's emotion. Employees with high empathic concern are not irritated by customers in terms of feeling or emotion, and only have a feeling about the customers, but do not feeling the same way as the customers (Davis, 1994). Ashforth\& Humphrey (1993) argued that emotional labor is closely related to the degree of considering the wellbeing and happiness of customers by service providers. Choi et al. (2006) found that empathic concern affects deep acting.

That is, although individuals with empathic concern do not agree with the emotion of others, they understand the emotion of others through a cognitive process and express their own emotion. Empathic concern is also one of the individual characteristics that are the causes of emotional labor, in that it expresses an emotional state different from the actual emotion.

Job emotion is the degree to which employees express their emotion during job performance and refers to the empathy occurring while performing their job. If employees empathize more while performing their job, it is more likely that they express their emotion. As a result, they are more likely to perceive the difference with the emotional display rule required by the organization. Thus, it can be expected that the job emotion of employees has a positive effect on emotional labor, which indicates the difference between the emotion they feel and the one the organization requires.

\subsubsection{Job Characteristics}

Hackman \& Lawler (1975) defined job characteristics as autonomy, task identity, skill variety, feedback, mutual contact and friendly relationship. Afterward, Hackman \& Oldham (1976) defined the following five core job characteristics by adding task significance to the existing characteristics: skill variety, task identity, task significance, autonomy and feedback.

Skill variety refers to whether a job requires a variety of activities, such as functions, talents, knowledge and skills. If a job itself can help employees diversely use skills or talents or frequently use or develop them, the employees find their jobs meaningful, and can experience more meanings as they use a higher level of functions. As the skill variety of employees increases, the diversity of their emotional display also increases. In service business, particularly, if the type of customers is diverse, the emotional display of the employees will become diverse, because they perform diverse emotional labors.

Task identity refers to the degree to which a job requires completion of a whole job or a part of the whole job. Organizational members think their jobs more meaningful when they can perform their job as a complete unit, rather than being responsible for some part of the job.

Task significance refers to the degree to which the job performed by individuals has a significant impact on the lives and works of other people both inside the organization or outside the organization. The individuals find their tasks meaningful when their tasks have an actual impact on the physical and psychological situation of others. Thus, individuals feel more significant when the degree to which 
their tasks contribute to the organization is greater.

Autonomy refers to the degree to which the job provides freedom, independence, and discretionary authority to individuals while performing task. A job with higher autonomy has the corresponding level of reasonability (Hackman \& Lawler, 1975).

Feedback is the degree to which a clear information on how effective the job performed by an individual is provided to the individual. That is, a feedback effect would be expected if individuals performing tasks could obtain information on the outcomes of their performance from the job itself, supervisors, co-workers and subordinates during the process of job performance. Feedback is the degree to which individuals clearly know the outcomes of their job in a direct and indirect manner.

With the feedback, employees can continue to think how can they be effective in their jobs, and through the process of performance feedback, employees are more likely to find their own job methods or processes without asking their supervisors.

Morris \& Feldman (1996) suggested that job autonomy reduces emotional dissonance and Wharton (1993) found that job autonomy decreases the emotional labor of employees.

\subsubsection{Organizational characteristics}

The organizational characteristics, as the antecedents of emotional labor, include organizational support system, social support, performance pressure and job satisfaction. Thomas \&Ganster (1995) suggested that the organizational support system creates an environment where a more predictable job environment is provided and co-workers can give helps each other, reducing the stress of the members.

Social support consists of support from supervisors, support from co-workers and support from family members, and refers to all positive supports that individuals can obtain from their interpersonal relationship (Cohen \& Marshall, 1978). Schneider \& Bowen (1985) reported that social support reduces the surface acting of emotional labor and supports from co-workers or supervisors create positive working conditions. The perception of employees that they are working in a supportive environment is associated with low stress and turnover intention and high job satisfaction and team work performance (Cropanzano et al, 1997; Eisenberger, Cummings, Armeli\& Lynch, 1997; Howes, Cropanzano, Grandey\&Mohler, 1999). Hochschild (1983) took unofficial meetings of air crews as an example of social support. He stated that air crews alleviate their stress by frankly expressing their annoyance and anger from the customers through such unofficial meetings. Abraham (1998) noted that employees can minimize the negative aspects of emotional labor and increase their job satisfaction through the processes of getting advice from supervisors and communicating their feelings with co-workers.

\subsection{Emotion work}

Emotion work is the starting point for the understanding of emotional labor. Hochschild(2003) used the term emotion work to refer to any attempt to modify the experience or expression of a consciously felt emotion. When the individual performs emotion work as a required part of his/her actual job performance it is called emotional labor. Callahan \&McCollum(2002) interprets that emotional work is appropriate for situations in which individuals are personally choosing to manage their emotions for their own non-compensated benefits. The term emotional labor is appropriate only when emotion work is exchanged for something such as wage or some other type of valued compensation. Wharton(1993) remarks that not only such actions are performed for wage; they are also under the control of others. Thus, emotional labor is under the control of organizations. Various scholars have conceptualized emotional labor in various ways. In the next section, these conceptualizations of emotional labor have been reviewed.

\subsection{Conceptualization of Emotional Labor}

The term emotional labor was first introduced by the American sociologist Arlie Russell Hochschild. Her research was in the airline industry, and focused particularly on the emotional work of flight attendants.

Since the concept of emotional labor introduced by Hochschild(1983), efforts to refine the concept of emotional labor have been made by many researchers(Ashforth\& Humphrey, 1993; Grandey, 200; Morris \& Feldman, 1996). In this section, in order to widen understanding of concept of emotional labor, this study examines some major researches that treated conceptualization of emotional labor in priority, and intends to refine the concept of emotional labor based on this.

Emotional labor was a term firstly coined by Hochschild(1979, 1983).She termed regulation of one's emotions to comply with occupational or organizational norms as "emotional labor". She defined emotional labor as "the management of feeling to create a publicly observable facial and bodily display; emotional labor is sold for a wage and therefore has exchange value"(Hochschild, 1983).

This definition explicitly delineates that service providers are required to regulate or manage their "feeling" emotions and dispaly those emotions for commercial purpose. These "display" emotions have economic value, which can be transformed into salaries, wages, or tips.

According to Hochschild, jobs with emotional labor have three criteria;1)they require face-to-face or voice-to-voice contact with the public 2)they require the worker to produce an emotional state in the client or customer 3)they allow the employer, through training and supervision, to exercise a degree of control over the emotional activities of employees(Hochschild, 1983).

Hochschild's perspective on emotional labor was an outgrowth of the dramaturgical perspective made popular by Irvin Goffman(1959). The dramaturgical perspective on 
behavior in organizations focuses on customer interactions as providing the performance stage for employees' impression management skills. Employees' efforts to manage their emotions appropriately for their respective organizational roles are seen as performances on the organizational stage. This emotion management is seen as a central part of the employee's job performance and meanings toward meeting organizational goals.

Ashforth\&Humphrey(1993) contributions to the area of emotional labor have propelled the study of emotions forward, since they include the role of social identity and integrate it into the study of emotions and their expression at work. They defined emotional labor as "the act of displaying the appropriate emotion"(Ashforth\& Humphrey, 1993). Their definition differs from Hochschild's(1983), since it emphasizes the actual behavior rather than the presumed emotions underlying the behavior.

Morris \&Feldman $(1996,1997)$ have also contributed to the growing literature on emotional labor in organizations by refining the conceptualization of emotional labor. They defined emotional labor as "the effort, planning, and control needed to express organizationally desired emotion during interpersonal transaction"(Morris \& Feldman, 1996).

Grandey(2000) provides another conceptualization of emotional labor in an attempt to clear up the apparent contradictions resulting from attempts in the literature to refine the construct of emotional labor. Grandey(2000) defined emotional labor as "the process of regulating both feelings and expressions for organizational goals".

The previous paragraphs have given an overview of the various theories an definitions currently available in the literature around the concept of emotional labor. As it can be observed, the debate about the nature of emotional labor is still ongoing, and no one specific theory gives a full picture.

Table 1. Definition of Emotional Labor

\begin{tabular}{|c|c|}
\hline Scholar & Definition \\
\hline $\begin{array}{c}\text { Hochschild } \\
(1983,1989)\end{array}$ & $\begin{array}{c}\text { the management of feeling to create a } \\
\text { publicly observable facial and bodily } \\
\text { display }\end{array}$ \\
\hline $\begin{array}{c}\text { Ashforth\& } \\
\text { Humphrey } \\
(1993)\end{array}$ & $\begin{array}{c}\text { the act of displaying the appropriate } \\
\text { emotion }\end{array}$ \\
\hline $\begin{array}{c}\text { Morris \& Feldman } \\
(1996,1997)\end{array}$ & $\begin{array}{c}\text { the effort, planning, and control needed to } \\
\text { express organizationally desired emotion } \\
\text { during interpersonal transaction }\end{array}$ \\
\hline $\begin{array}{c}\text { Grandey } \\
(2000)\end{array}$ & $\begin{array}{c}\text { the process of regulating both feelings and } \\
\text { expressions for organizational goals }\end{array}$ \\
\hline $\begin{array}{c}\text { Krual\& Geddes } \\
(2000 \mathrm{a})\end{array}$ & $\begin{array}{c}\text { what employees perform when they are } \\
\text { required to feel or at least project the } \\
\text { appearance of certain emotions in order to } \\
\text { produce }\end{array}$ \\
\hline $\begin{array}{c}\text { Diefendorff\& } \\
\text { Richard(2003) }\end{array}$ & $\begin{array}{c}\text { the management of emotions as part of the } \\
\text { work role }\end{array}$ \\
\hline $\begin{array}{c}\text { Johnson } \\
(2007)\end{array}$ & $\begin{array}{c}\text { the expression of organizationally desired } \\
\text { emotions by service agents during service } \\
\text { encounters }\end{array}$ \\
\hline
\end{tabular}

It was found that typical researches have not clearly agreed on the conceptual definition of emotional labor, and there have arisen conceptual differences due to a matter of perspective. The point that preceding researches commonly claim is that individuals can regulate their emotional expressions at work. Emotional labor involves active strategies to modify, create, and alter the expression of emotions in the context of paid employment. Thus, emotional labor is the process of regulating the expression of emotions for achievement of organizational goals and the employee is paid for this labor.

\subsection{Surface Acting (SA) \& Deep Acting(DA)}

SA involves employees simulating emotions that are not actually felt, by changing their outward appearances (i.e., facial expression, gestures, or voice tone) when exhibiting required emotions. Using the SA technique, people alter the outward expression of emotion in the service of altering their inner feelings. By changing facial or bodily expressions, such as slumped shoulders, bowed head, of drooping mouth, inner feelings can be altered to a corresponding state(Hochschild, 1993).

DA occurs when employees' feelings do not fit the situation; they then use their training or past experience to work up appropriate emotions. Unlike SA, DA involves changing inner feelings by altering something more than outward appearance. In SA, feelings are changed from "outside in", whereas feelings are changed from the "inside out" in DA(Hochschild, 1993). Hochschild(1983) classified DA as (1) exhorting feeling, whereby one actively attempts to evoke or suppress an emotion, and (2) trained imagination, whereby one actively invokes thoughts, images, and memories to induce the associated emotion(thinking of a wedding to feel happy or a funeral to feel sad). In other words, employees use their training or past experiences to help conjure up appropriate emotions or responses(empathy, cheerfulness) for a given scene(Kruml\& Geddes, 2000a).

The two strategies suggested by Hochschild(1983), Deep Acting(DA) and Surface Acting(SA), have a common ground in that they both are a kind of complementary emotional labor strategy that employees use when they cannot naturally express their emotion (Diefendorff, Croyle\&Gosserand, 2004), and both the two let employees perform emotional labor in the same way as normative emotion that an organization requires them to express to customers (Ashforth\& Humphrey, 1993; Grandey, 2003).

However, intentions of the two strategies are definitely different from each other.

SA is to make only the visual aspect ofemployees' emotion correspond to the emotional expression principle of an organization. Accordingly, emotional dissonance could be easily induced (Ashforth\& Humphrey, 1993; Brotheridge\&Grandey, 2002; Grandey, 2003; Zapf, 2002).

DA is not only to create externally expressed emotion but to change internal emotion in the direction of the emotional 
expression principle. For this, empathy, and thoughts and images that trigger specific emotion are actively utilized (Ashforth\& Humphrey, 1993; Brotheridge\&Grandey, 2002; Grandey, 2003; Zapf, 2002).

The two emotional labor strategies suggested by Hochschild(1983), DA and SA, have a common ground that both the two attempt to perform emotional labor in the same way as normative emotion that an organization requires employees to express, when they cannot appropriately express their emotion (Ashforth\& Humphrey, 1993; Grandey, 2003).

However, these two emotional labor strategies have a clear difference. The SA strategy attempts to make only external expressions correspond to normative emotion required by an organization regardless of employees' internal emotion. This could cause emotional dissonance due to conflicts between employees' internal feeling and normative emotion(Rafaeli\& Sutton, 1987). In this light, the SA strategy is different from the DA strategy, and can be named 'fake in bad faith'. The DA strategy tries to change even employee's internal emotion in the direction of normative emotion. In this regard, the DA strategy can be named 'fake in good faith'(Rafaeli\& Sutton, 1987).

Existing studies showed that SA results in negative emotional labor and DA results in positive emotional labor. For example, they reported that while SA is related to negative results such as depersonalization, emotional exhaustion, or dissatisfaction, DA is related to positive results such as sincerity or a sense of fulfillment (Brotheridge\&Grandey, 2002; Brotheridge\& Lee, 2002, 2003; Diefendorff\&Gosserand, 2003; Grandey, 2003; Grandey et al, 2005).

DA and SA have different results and effectiveness. That is, because while DA is not only to create externally expressed emotion but to change even internal emotion in the direction of the emotional expression principle, SA is only to make the visual emotional aspect correspond to the organizational emotional expression principle (Hochschild, 1983), DA is highly relevant to a positive outcome variable and SA is highly relevant to a negative outcome variable.

Grandey(2000) suggested a conceptual model by using emotion regulation theory through characterizing emotional labor. This emotion regulation theory was suggested by Gross(1998), which indicates 'the process that influences what emotion individuals have, when they feel that emotion, how they experience emotion, and how they express it'. Grandey(2000) emphasized the importance of SA and DA during the process of performing emotional labor. That is, he argued that SA and DA could bring about both positive and negative results upon emotional labor. For example, SA could have a negative effect on job satisfaction due to the discord that individuals experience. On the other hand, DA could positively influence job satisfaction because it makes individuals feel a sense of fulfillment that they have expressed their emotion appropriately. Grandey(2000) includes not only the outcome variable of emotional labor but situational, individual, and organizational factors that influence emotional labor.

\subsection{Dimensions of Emotional Labor}

Hochschild(1979, 1983)categorized those performing emotional labor based on the 'acting' they were performing. Hochschild describes two types of emotional acting: surface acting and deep acting. Surface acting involves employee's simulating emotions that are not actually felt, by changing their outward appearances(i.e, facial expression, gestures, or voice tone) when exhibiting required emotions. Deep acting occurs when employee's feelings do not fit the situation; then they use their training or past experience to work up appropriate emotions.

Hochschild discussed surface acting and deep acting as key features of emotional labor, however, several researchers suggested that emotional labor is a multidimensional construct and may involve strategies other than surface acting and deep acting.

Ashforth\&Humphrey(1993) argued that employees must do surface acting or deep acting in order to express the expected emotions. However, they took the definition of emotional labor a step further by including a third category of emotional labor called expression of genuine emotion. They stated that conceptualizing emotional labor as surface acting and deep acting alone dismisses the possibility of employees spontaneously and genuinely experiencing and displaying appropriate emotions.

Morris \&Feldman(1996) conceptualize emotional labor in terms of four distinct dimensions; 1)the frequency of appropriate display 2)attentiveness to required display rules $3)$ variety of emotions required to be displayed 4)the emotional dissonance generated as a result of having to express organizationally desired emotions that are not genuinely felt. Later, in their empirical research on antecedents and consequences of emotional labor, emotional labor was identified into three dimensions: 1)frequency 2)duration 3)emotional dissonance.

Brotheridge\&Lee(2003) developed the six faceted Emotional Labor Scale(ELS) based on the theories of Hochschild(1983) and Morris \& Feldman(1996). Their ELS measures the " intensity, frequency, variety of emotional display, surface acting, deep acting and the duration of interaction.

Examining preceding researches dealing with emotional labor dimensions, since Hochschild first suggested surface acting and deep acting, emotional labor dimensions have not been clearly determined until today. Although plenty of researches on emotional labor dimensions are presently being conducted, no agreement has been brought about yet. Many of researches have dealt with emotional labor dimensions by using surface acting and deep acting that only focus on emotional expressions, and the results are also limited. Thus, this research, to approach emotional labor multi-dimensionally, composed emotional labor dimensions with surface acting, deep acting, frequency, 
strength, and diversity.Hochschild(1979, 1983)categorized those performing emotional labor based on the 'acting' they were performing. Hochschild describes two types of emotional acting: surface acting and deep acting. Surface acting involves employee's simulating emotions that are not actually felt, by changing their outward appearances(i.e, facial expression, gestures, or voice tone) when exhibiting required emotions. Deep acting occurs when employee's feelings do not fit the situation; then they use their training or past experience to work up appropriate emotions.

Hochschild discussed surface acting and deep acting as key features of emotional labor, however, several researchers suggested that emotional labor is a multidimensional construct and may involve strategies other than surface acting and deep acting.

Ashforth\&Humphrey(1993) argued that employees must do surface acting or deep acting in order to express the expected emotions. However, they took the definition of emotional labor a step further by including a third category of emotional labor called expression of genuine emotion. They stated that conceptualizing emotional labor as surface acting and deep acting alone dismisses the possibility of employees spontaneously and genuinely experiencing and displaying appropriate emotions.

Akey contribution of Ashforth\&Humphrey(1993)theory of emotional labor is their emphasis on the observable expressions of emotions rather than the internal management of emotions. They focused on the outcomes process instead of actual processes themselves. They argued that surface acting and deep acting by themselves focus on the effort of trying to express the desired emotions, and ignore the outcomes such as how genuine or sincere the emotion appears to customers and affects on customers(Ashforth\& Humphrey, 1993).

Researchers have used different approaches to understand the dimensionality of emotional labor. Some treat emotional labor as a one-dimensional construct solely concerned with the intensity and frequency of emotional displays(Hochschild, 1983; Wharton 1993; Abraham, 1998), and others see emotional labor as a multi-dimensional construct(Morris \& Feldman, 1997; Grandey, 1999; Schaubroeck\& Jones, 2000; Kruml\& Geddes, 2000a).

Among those researchers who assert that emotional labor is a multi-dimensional construct, there are different opinions about the numbers of dimensions of emotional labor. Different dimensions capture different facets of emotional labor.

Morris \&Feldman(1996) conceptualize emotional labor in terms of four distinct dimensions; 1)the frequency of appropriate display 2)attentiveness to required display rules 3)variety of emotions required to be displayed 4)the emotional dissonance generated as a result of having to express organizationally desired emotions that are not genuinely felt. Later, in their empirical research on antecedents and consequences of emotional labor, emotional labor was identified into three dimensions: 1)frequency 2)duration 3)emotional dissonance. However, other researchers have criticized Morris \& Feldman's approach and raised some conceptual and methodological concerns regarding these dimensions and how they were identified. Grandey(1999) argued that frequency, duration and variety of emotional labor provide information about the job demands on employees' emotional displays. These three factors capture only the presence of emotional labor, but fail to further explain the emotion management process of the employee. Kruml\& Geddes argued that these three dimensions failed to conceptually link to their definition of emotional labor.

In an effort to integrate previous perspectives, Brotheridge\&Grandey(2002) restructured emotional labor into two categories. One focuses on the characteristic of the job and the other emphasizes employees' emotion management process. The former is called "job-focused emotional labor' which includes the frequency, duration, variety, and intensity of emotional labor and display rules. The latter is called "employee-focused emotional labor" which includes surface acting and deep acting.

\subsection{Negative and Positive Outcomes of Emotional Labor}

\subsubsection{Positive outcomes of emotional labor}

Emotional labor can have a positive psychological effect on employees (Pugliesi, 1999). Previous studies on emotional labor were performed under the assumption that employees are forced to feel other emotions than their own emotion, which then act as stressors by themselves, focusing on the psychological aspect of employees. However, the positive outcomes of emotional labor are based on the view that emotional labor can obviously create positive outcomes because there can surely be potential benefits of emotional labor (Wouters, 1989).

This view is explained by a theory called the facial feedback hypothesis presented by James (1984), stating that the subjective emotion of an individual occurs as a physical response is created by stimulus. This perspective started to be accepted as Zajonc (1985) described emotional change based on the vascular system and Adelmann (1989) emphasized a physical response in terms of psychology. He argued that the change of expression on the face not only causes the current emotion to be surfaced, but also creates change in emotion, suggesting that the relationship between emotion and cognition can be a mutual direction.

As for the positive outcomes of emotional labor, Wharton (1993) found a positive association between emotional labor and job satisfaction in hospital employees. A study on bank employees by Shmutte (1999) also found a positive relationship between positive emotional display and job satisfaction, which empirically supports the assertion of Wouters (1989) that emotional labor not only incurs costs, but also creates benefits. Ashforth and Humphrey (1993) viewed emotional labor as being positive because emotional labor plays the role of strengthening the mutual relationship between employees who perceive it. That is, once employees get used to emotional labor, they put some 
distance from the unpleasant situation, which in turn reduces their stress and increases satisfaction. Rafeli and Sutton (1989) found that employees who have to show their smiling faces have generally a low level stress and a high level of job satisfaction. The studies of Morris and Feldman (1996), who have had the most considerable contribution with regard to emotional labor, also showed that the frequency of emotional display, a sub-factor of emotional labor, has also a positive effect on job satisfaction.

\subsubsection{Negative outcomes of emotional labor}

Studies on emotional labor generally focus on the negative outcomes of emotional labor. The theoretical base of the authors who argue for the negative outcomes of emotional labor is the alienation hypothesis. This hypothesis is a theory used by Hochschild (1983) who presented emotional labor as a conceptual variable for the first time.

Although organizations require their employees to always express friendly emotions to their customers, the employees do not follow the requirement in reality. Thus, employees recognize a disparity between the emotions their organization pursues and their own. If the disparity continues, they recognize themselves as liars and are afraid of expressing their emotion in a normal emotional situation. As a result, they find it difficult to form an emotional relationship with others, and become isolated from society.

Through interviews and observations with air crews, Hochschild (1983) revealed that emotional labor causes negative psychological outcomes. He argued that continued performance of emotional labor makes employees blame themselves that they are hypocritical, making it difficult for them to actually express their emotions, even after they return to their daily lives from their jobs (Jones, 1997).

Studies on the negative outcomes of emotional labor argue that it is unreasonable to suggest that the positive outcomes of emotional labor can be drawn because there is a weakness that the variables that can confirm the positive outcomes of emotional labor are limited only to job satisfaction. Through a comparative analysis between the emotional labor group and non-emotional labor group, Adelmann (1989) found that the job satisfaction, self-esteem and health condition of the emotional labor group are low, and that there are more people who feel depressed in the group. Morris and Feldman (1996) argued that emotional dissonance, a sub-factor of emotional labor, experiences emotional exhaustion and causes physical and psychological problems, negatively affecting job satisfaction and organizational commitment. Schaubroeck and Jones (2000) showed that physical symptoms as well as emotional exhaustion can be caused as employees spend a lot of efforts and energy to hide their positive or negative emotion while providing services. Further, Pugliesi and Shook (1997) and Brotheridge and Grandey (2002) found that emotional labor decreases job satisfaction and increases job stress.
With regard to the outcomes of emotional labor, the present study investigated the theoretical bases of positive and negative outcomes and examined the studies that empirically analyzed them. However, the authors of the empirical analyses argued that both outcomes can be drawn, rather than emphasizing either side of the outcomes. In most cases, however, they regarded emotional labor as the cause of stress and considered it the antecedent causing negative outcomes.

\section{Summary}

Clearly, though a considerable amount of effort has been devoted to understanding what is emotional labor, there is a lack of clear definitions and valid measures. The existing study on emotional labor is not far off the subject treated in early study. Also, as researchers are explaining various conceptualizations and processes about emotional labor with quite different theoretical viewpoints, there are problems such as drawing mixed research results. As these researchers are testing diverse precedence factors and result variables on how they define and measure emotion management with opposing sides against one another, it is difficult to measure research results. Though this is a common phenomenon undergone in the process of theoretical development, for the development of a research on emotional labor, a research to approach emotional labor more synthetically is necessary here and now. Perceiving these problems, this study integrated and refined the conception and variables of emotional labor based on preceding researches. As each research has developed by suggesting new ideas and directions to complement shortcomings of preceding researches, this study intends to focus on integrating and refining the concepts of preceding researches in this context. This paper presents a review of the literature regarding the emotional labor. This paper explains the concept of emotional labor, dimensions of emotional labor and consequences of emotional labor. The goal of the study is to integrate the conceptualization of emotional labor and its components through the examination of the previous studies, presenting researchers subsequent academic discussions. Some subtle differences were found in the concept of emotional labor and it components as suggested in previous study, differing in the perspectives from the point of view from any direction and not being completely contradictory to each other. Moreover, the differences might be recognized as a conceptual refinement and the expansion of the range of each study based on previous investigations. This paper contributes to the existing literature by assimilating different works done in this domain and providing a comprehensive understanding of emotional labor. That is, this study arranges systematically and examines theories on emotional labor suggested hitherto, and suggests a future direction of research on emotional labor on the basis theory. The result obtained through this study will contribute to developing the theory of emotional labor. 


\section{REFERENCES}

[1] Hochschild, A. R. The Managed Heart, Berkeley \& Los Angeles, CA: University of CaliforniaPress, 1983.

[2] Ashforth B. E. \& Humphrey, R.H."Emotional Labor in Service Roles: The Influence of identity".Academy of Management Review, 1993, 18(1), 88-115.

[3] Morris J. A. \& Feldman D. C."The dimensions, antecedents, and consequences of emotional labor",Academy of Management Review, Vol.21, 1996.

[4] Grandey, A. A. Emotion regulation in the workplace: A new way to conceptualize emotional labor. Journal of Occupational and Health sychology, 2000, 5(1), 95-110

[5] Maslach, C. Burnout(1993), A ultidimensional Perspective, In: Schaufeli, W. B. Maslach, C. \& Mark T.(Eds) Professional Burnout: Recent developments in theory and research, Washington, DC: Taylor \& Francis 